\title{
THE THEORY OF MONEY VALUE AND MONETARY EVOLUTION FOR SIMMEL AND MISES
}

\author{
LEONIDAS ZELMANOVITZ*
}

\begin{abstract}
Resumen: Este trabajo empieza planteando que Simmel es un puente de unión entre las teorías de valor del dinero de Menger y Mises, y que su contribución es importante por sí misma. En este sentido, destaca su idea de que el dinero se vuelve más abstracto con el desarrollo de la sociedad. Posteriormente, describe sucintamente las teorías del valor del dinero de Menger, Mises y Simmel, poniendo énfasis en las contribuciones de Simmel acerca de la teoría de valor del dinero de Mises. Respecto a la teoría del valor del dinero de Simmel, se plantea que supuso un paso adelante en relación a Menger, al afirmar que el valor del dinero no es solamente subjetivo sino ínter-subjetivo. Esta afirmación es un paso necesario en su argumento de que existe una tendencia hacia formas más abstractas de dinero conforme la sociedad se torna más compleja.
\end{abstract}

Palabras clave: Teoría del valor, Escuela Austriaca, definición de dinero, sistema de pagos.

Clasificación JEL: B10, B13, E40, E42.

Abstract: The essay starts positioning Simmel as a bridge between the money value theories of Menger and Mises, and claiming that his contribution is important in its own right; notably, his idea that money evolves towards more abstract forms as society becomes more complex. It states that this trend exists and that its course has not yet been completed. After that, the theories of money value of Menger, Mises and Simmel are succinctly described, with emphasis on the contributions to Mises' theory of money value that can be traced back to Simmel. About Simmel's theory of money value, it is argued that Simmel went one step further than Menger in stating that value is not only subjective but also inter-subjective; such a move is understood as a necessary step in his argument that there is a trend towards more abstract forms of money as society evolves.

* Liberty Fund Fellow. Email: lzelmanovitz@libertyfund.org 
Key words: Value Theory, Austrian School, Definition of Money, Payment Systems.

JEL Classification: B10, B13, E40, E42.

\section{I \\ INTRODUCTION}

Georg Simmel's Philosophy of Money brings an account about how money evolves, that account can be summarily described as a trend towards more abstract forms of media of exchange. It is extremely important for the reasoning presented with this paper to note that Simmel's account of monetary evolution is tightly intertwined with his theory of money value in ways that I expect to make clear in the following pages. Having that in mind, it is relevant to question the importance of Simmel for monetary thought. In terms of history of ideas, Simmel's theory of money value as presented in his 1900 Philosophy of Money is situated after Menger's 1871 Principles of Economics and before Mises' 1912 Theory of Money and Credit. It is the contention of this paper that Simmel's ideas about money were influenced by Menger's and by its turn influenced Mises'. ${ }^{1}$ But Simmel's ideas are also relevant in their own right. One of the topics which Simmel is most recognized for today, perhaps the main theme of his entire intellectual career, is the connection between modern urban societies with individuality. Simmel argues that the idea of individuality that is shared by modern Western societies is only possible in the "Great Society", in the open society with intense and extended division of labor, with commercial relations among strangers, with the intense urban life that is a common feature now of Western countries. However, that kind of society is only

1 The similitude between Simmel's and Mises' monetary theories in general as well as their theories of knowledge and conceptions about the truth was already pointed out by Professor Oscar Vara Crespo, who in his 2004 paper published by Procesos de Mercado also quotes Laidler and Rowe referring to the influence of Menger in Simmel's monetary theory (Crespo 2004: 224). This paper has a more limited scope, though; in this paper just the conceptions about the theory of money value of Menger, Simmel and Mises are compared. 
possible with increasingly more sophisticated (abstract, in his terminology) forms of exchanges.

For Simmel, it is only in a modern urban setting that it is possible to exercise an individualistic life in its plenitude. And the privacy and independence that individuals have in a modern urban environment are only possible in a complex monetary society (Simmel 1971: 326); and in this way he argues for the relation between individualism and money. It is not any sort of monetary arrangements that would allow that kind of society to happen, not to mention prospering. Simmel, therefore, establishes a relation between monetary arrangements, modernity and individualism and argues that that relation is part of the backbone of the social arrangements most adequate to the exercise of individual freedom and responsibility.

There is no need to emphasize that for Mises there is also a relation between civilized mankind and money (Mises 2007: 209). But the similitude between Mises and Simmel thoughts on money that is intended to be pointed out is the one related to the subjective source of money value and the evolutionary character of money.

\section{An identifiable trend towards abstraction}

It may be claimed that, since a medium of exchange was introduced in society, it has evolved to more abstract forms. From cattle and other commodities to precious metals in bullion, from bullion to coins, from coins to redeemable banknotes, from redeemable notes to fiat money, from fiat money to checking accounts, and from checking accounts to credit cards; all the evolution in the monetary institutions have been in one direction, from more concrete forms of medium of exchange to more abstract ones. However, this paper is not the proper place for inquiries about why that is so; for the purpose of this paper, it is suffice to understand that this trend exists. But, if Simmel's argument, in his The Philosophy of Money, that all goods that can be bought with money constitute one part (of the realm of economics) and money constitutes the other part is accepted, then: 
money (may be) defined as «abstract» value. As a visible object, money is the substance that embodies abstract economic value (Simmel 2001: 120).

And as the embodiment of abstract economic value, it is only natural for money to become more and more abstract, at the pace that technology and trust in new monetary instruments evolve in society. ${ }^{2}$

\section{II}

\section{VALUE OF MONEY FOR MENGER}

For Menger, the value of the monetary merchandise is intrinsically related to its capacity to perform what is perceived to be the purpose of money in society, that is, to facilitate, by indirect exchanges, the division of labor. Therefore, Menger's theory of money value may be deduced from his postulates about that.

\section{The Carl Menger's GAMOE definition}

Because not every good in the market is as saleable as the others, in real life, the more saleable goods became accepted by the individuals in exchange for the goods they produced as a medium to acquire other goods which they needed. All the other functions of money derive from this primary one, confused with the very concept of money: the Generally Accepted Medium of Exchange,

2 The monetary institutions of a society do not exist in a vacuum; they change according to the stage of development of the society in which they operate. For instance, it is reasonable to assume that starting during the late Roman Empire and continuing well into the Dark ages, the quality of money deteriorated just as all other relevant institutions for the maintenance of a urban society with a high level of division of labor in an extended region (almost the totality of the «known world» at the time) did. So, it must be acknowledged that the development of monetary institutions follows the development of their respective societies; but that correlation between monetary and other institutions must not be understood as in contradiction to the above-mentioned trend for more abstraction in money. Whenever a society is evolving, its money is evolving in the direction of more abstract forms. 
or the «GAMOE» definition as firstly developed by Carl Menger (Menger 1994: 280) and widely accepted today.

Money for us is a «unit of account», a «standard of value» because it is the preferred medium of exchange. We could have a unit of account, a standard of value, that would not be the generally accepted medium of exchange, but in this case the traders would be required to do triangular calculus at each transaction.

Money is a «stock of value» because not all exchanges happen simultaneously and the individuals demand the possession of some easily saleable good. What good fits better this purpose? The generally accepted medium of exchange does, i.e., money.

Originally, money relies on the trust of the individuals accepting a «monetary» good as an instrument to acquire a certain amount of desirable goods. And any time we are confronted with questions about money, we must remember money's origins in order to understand its desired properties.

\section{Money and the Division of Labor}

The main difference between a monetary economy and a barter economy is the limitations of the latter to fully allow the division of labor. A monetary system must be a tool to allow and implement the division of labor. The more a system allows the division of labor, the more proper it is.

Besides the absence of money, the division of labor may be constrained by other factors such as the size of market, the cultural background of people, the extent in which property rights are enforceable, et cetera, but it is not part of our goals to inquire about these other constraints. Suffice to say that ceteris paribus, i.e., (hypothetically) for societies mainly with same size markets and same cultural background, it is reasonable to assume a correlation between the intensity in which certain properties are present in the money used by a community and the extension of the division of labor in such community or, in other words, the complexity of its economic activities. It is a relation that works in both ways: a society that lacks labor specialization does not need monies with all the qualities of good money, and without good money labor 
specialization cannot be further developed. It is not any money that will allow one society to develop industrial activity not to mention complex capital markets. It is worth mentioning that at the time of the Late Roman Republic and Early Roman Empire, they had monies good enough to enable them to run an economy based on trade, agriculture and slavery for centuries, but even that primitive economy crumbled with the less adequate monies of the late Empire. ${ }^{3}$

\section{The origin of money for Menger and the nominalist dissent}

What made a coined piece of gold (or any other rare metal for that matter) better money than a bag of salt? Gold coins (used as a proxy for rare metals in this paper) were a more convenient medium of exchange than bags of salt, they were easier to carry, cheaper to store, and gold has higher intrinsic value. The introduction of money in general and coined gold in particular was due to the convenience of their use, the desirability of their properties as we can imagine from something voluntarily adopted by the people. If the «monetary» goods have the properties desired by the money holders, these goods will ease the exchanges by diminishing the costs of transacting and with this enhance the labor division.

\footnotetext{
${ }^{3}$ At least from the second century BCE on (possibly earlier), Roman institutions were adequate to support long-term financial transactions (Andreau 1999: 152), as M. Rostovtzeff wrote:

...The monetary chaos which reigned in the Greek cities and the Hellenistic monarchies before the period of Roman domination in the East was greatly reduced by the introduction of the paramount currency of the Roman state (Rostovtzeff 1926: 171).

Later, however, at the time of the Emperor Alexander Severus (222-235 CE), the situation had deteriorated immensely as described by Rostovtzeff:

...the state resorted to compulsion and to organized robbery. As is well known, one of the most pernicious devices was the abuse of its monopoly of coinage. Looking round for new resources, the state did not shrink from pure forgery by debasing its currency, which the ever-increasing use of alloy made more and more worthless. The result was a tremendous increase in prices and the ruin of sound business (Rostovtzeff 1926: 380).
} 
Menger already makes clear that money in general and coined money are not the same thing and that, generally speaking, money has a spontaneous origin:

The origin of money (as distinct of coin, which is only one variety of money) is, as we have seen, entirely natural and thus displays legislative influence only in the rarest instances. Money is not an invention of the state, it is not the product of a legislative act (Menger 1994: 261).

The dissent with Menger's subjectivist and evolutionary explanation for the origin of money value and the introduction of money in society was first expressed by Friedrich Knapp. Knapp starts his argument by accepting the claim that the medium of exchange at a certain moment in history was valued by its weight. However, he argues that it was a long gone historical event and now, the value of money is given by the state, for Knapp:

In the German language money (geld) always means a formed (morphic) means of payment; but there are morphic means of payment that are pensatory. This however is at a lower stage of development which will be outgrown in the curse of history (Knapp 2003: 38).

For Knapp, money in a «modern sense» has only nominal value, a value that is «declared» by the State:

For the more exact observer money in the modern sense first comes into being when the morphic means of payment have their validity settled by proclamation and becomes Chartal. So we get the following answer to the question we have asked. Money always signifies a Chartal means of payment. Every Chartal means of payment we call money. The definition of money is therefore «a Chartal means of payment» (Knapp 2003: 38).

Menger, however, has an answer for the dissenters' claims, the government can increase the monetary attributes of particular 
goods, exercising coercion, but it cannot give monetary characteristics to any good:

But if, in response to the needs of trade, a good receives the sanction of the state as money, the result will be that not only every payment to the state itself but all other payments not explicitly contracted for in other goods can be required or offered, with legally binding effect, in units of that good...

Thus, the sanction of the state gives a particular good the attribute of being a universal substitute in exchange, and although the state is not responsible for the existence of the money-character of the good, it is responsible for a significant improvement if its money-character (Menger 1994: 262).

In summary, already in Menger we find a theory of money value in which the value of the monetary merchandise is not defined by law, is not invented by human design, but it evolves spontaneously as «each economizing individual» finds in his interest to engage in indirect exchange, exchanging his goods for something that he does not need directly, but that he subjectively evaluates as a better instrument to procure the goods that he does need (Menger 1994: 260). Once presented the theories of money value of Simmel and Mises, the connection between their contributions and Menger's to the theory of money value will be made clear.

III

\section{MISES' THEORY OF MONEY VALUE}

For analytical purposes, it is advisable to, un-chronologically, describe succinctly Mises theory of money value before Simmel's. Mises' theory of money value can be described as subjective and catallactic, that is, it is a result of the evaluations made by each individual in the market. 


\section{The subjectivity of money value for Mises}

First, how does the process by which the individuals determine the value of different goods operate according to Mises? Is this process dependent on money? For Mises, the determination of value happens only in relation to other available goods, it is never a case of absolute value, only of relative value, a process in which the different goods are arranged in order of their significance, and here Mises is found making a direct reference to Simmel:

The process of valuation remains fundamentally the same whether the question is one of transforming labor and flour into bread in the domestic bake house, or o obtaining labor and flour exchange for clothes in the market». «For this reason it has been said that every economic act may be regarded as a kind of exchange».

* See Simmel, Philosophie des Geldes, $2^{\text {nd }}$ Edition, Leipzig, 1907, p. 35 (Mises 1980: 52).

For Mises, the economic activity has no other basis than the value scales utilized by the individuals acting in the market, upon which the exchange ratios of different commodities are established. In stating that «...valuation in no way consist in a comparison of two "quantities of value"» Mises creates the basis to discredit the nominalist/statist conceptions of money value; «If it is impossible to measure subjective use-value, it follows directly that it is impracticable to ascribe "quantity" to it» (Mises 1980: 58).

Although there is no direct quote of Simmel in the following passage, the version of subjectivism adopted by Mises in it is certainly not derived from Menger:

Modern value theory is based on the fact that it is not the abstract importance of different kinds of needs that determines the scale of values, but the intensity of specific desires (Mises 1980: 59).

To conclude this section about the subjectivity of money value for Mises, the relative, the non-absolute, character of money value may be stressed, since it is at the center of his criticism of nominalism: 
What has been said should have made sufficiently plain the unscientific nature of the practice of attributing to money the function of acting as a measure of price or even of value. Subjective value is not measured, it is graded (Mises 1980: 61).

\section{The sense in which money has an objective value for Mises}

It is an idea common to the three authors discussed in this paper that the value of money is a consequence of a subjective act of evaluation; however, it is also accepted by them that money has, in a sense, an objective value, as well. This objective value of money is the value which is employed in given transactions. If you pay $\$ 12$ for a haircut, it can be said that the amount of money involved in that transaction can be objectively determined:

Nowadays exchange is usually carried on by means of money, and since every commodity has therefore a price expressible in money, the exchange value of every commodity can be expressed in terms of money (Mises 1980: 61).

For Mises, the role of money as a standard of value, as a tool for economic calculation is of a distinct value from its value as a medium of exchange:

Because the market enables any commodity to be turned into money and money into any commodity, objective exchange value is expressed in terms of money. Thus money becomes a price index, in Menger's phrase (Mises 1980: 62).

And money in this role as an objective "price index» becomes an indispensable intellectual tool:

Money has thus become an aid that the human mind is no longer able to dispense with in making economic calculations (Mises 1980: 62).

As mentioned before, the main attribute of money according to Mises' theory of money value is that the source of money value 
is subjective. But things are more subtle than that: on one hand, for Mises (as for Menger and Simmel as well) there is also an objective value, that is, the value that money has in a given transaction:

If, in accordance with an objective theory of value, the possibility of an objective concept of commodity values is accepted, and exchange is regarded as the reciprocal surrender of equivalent goods, then the conclusion necessarily follows that exchange transactions must be preceded by measurement of the quantity of value contained in each of the objects that are exchanged. And it is then an obvious step to regard money as the measure of value (Mises 1980: 51).

But on the other hand, despite acknowledging that in each given transaction there is an identifiable money value that is attributed to the merchandize sold or bought, it does not explain at all why that particular agent is willing to surrender that amount of money for the merchandise, therefore, a different starting point is necessary:

But modern value theory has a different starting point. It conceives of value as the significance attributed to individual commodity units by a human being who wishes to consume or otherwise dispose of various commodities to the best advantage (Mises 1980: 51).

\section{Abstract value of money in Mises}

Mises starts his discussion about what is abstract in money stating what it has of concreteness, that is, its purchasing power:

The central element in the economic problem of money is the objective exchange value of money, popularly called its purchasing power (Mises 1980: 117).

Next, Mises explains that, contrary to what happens with all other merchandises that have a use-value per se, in the case of 
money, subjective use-value and subjective exchange value coincide. Mises explains that both are derived from its objective exchange value, for money has no utility other than that arising from the possibility of obtaining other economic goods in exchange for it:

It is impossible to conceive of any function of money, qua money, that can be separated from the fact of its objective exchange value (Mises 1980: 118).

For Mises, before an economic good begins to function as money it must already possess exchange value based on some reason other than its monetary function. But then, Mises explains that money that already functions as such may remain valuable even when the original source of its exchange value has ceased to exist and then he concludes, quoting Simmel that:

Its value then is based entirely on its function as common medium of exchange. (See Simmel, Philosophie des Geldes, $2^{\text {nd }}$ Edition, Leipzig, 1907, p. 115.)

So, for Mises, whatever was the "original source» of the exchange value of money, money «qua money» has its value based «entirely» on its role as the medium of exchange. The value of some merchandise as the instrument for indirect exchanges arises from the subjective evaluation of all economic agents; that merchandise, whose value may have lost all its relation with a previous origin of value, now acquires objectively a value in exchange.

\section{Monetary disturbances}

But then there is another problem, can we talk about a "general price level»? This issue can be better understood by paying attention to the problem of creating a price index as described by Mises in his The Theory of Money and Credit. In order to take any measurement, one must assume that the gauge will not 
change, or as Mises puts it, that the «commodity price of money" (Mises 1980: 216) will not change. But if we have more than one commodity, it will be only possible if we (unrealistically) assume that there are no relative price variations among the different commodities. If we add to this problem the fact that the quantity of available goods is not defined because we do not know what the desired goods are, to begin with, ${ }^{4}$ we cannot even talk about pondering the quantities of different goods; then it becomes clear that no price index is reliable to reflect accurate changes in the "general price level» since there is no such thing. ${ }^{5}$

Therefore, for Mises, the value of money is not an absolute value, it has no other source than the subjective evaluations of the economic agents in the market about its utility as medium for the indirect exchanges and it should be measured in relation to every good and not against all goods and services at the same

4 In order to measure changes in the "general price level», should we take into account the stock of real estate properties, or the stock of securities or the stocks of exportable goods and services existing in other countries? Should we take into account the spare capacity of producing desirable goods domestically and abroad? In The Theory of Money and Credit, Mises (Mises 1980: 512) comments on Schumpeters' attempt to formulate a catallactic claim theory for money. Professor Mises criticizes Schumpeter's claim analogy for money based on the fact that the analogy with any other claim, like a movie theater ticket, does not hold because (a) we do not know the amount of goods that there are on the market to be acquired in exchange for money (the equivalent of the total seats in the movie theater analogy) and (b) we do not know the total amount of money in circulation, because we do not know the amount that individuals want to hold, to hoard or to constitute their comfortable level of reserves.

5 Not long ago I was told to be «too strictly Austrian» about «aggregation» in general and the "general price index» in particular, and that aggregation and the general price index are respectively an old and useful practice and concept. I do not disagree with that. As I see it, aggregations in economics serve the logical purpose of generalizations in language, they are extremely useful for reasoning about categories of entities, but my point is that they suffer from the same shortcomings, that is: broad generalizations tend to lose accuracy in describing their components. For example, the category of four legged animals is less precise than the category of equines that is less precise than the category of horses, et cetera. Therefore, the broader the generalization is, the more difficult it is to characterize the attributes of its components. About general price indexes, I just don't see them as very precise, but I agree that they help to explain many economic phenomena; therefore, I should limit my stance to the skepticism about the possibility of practicing proper meaningfully inflation targeting policies using price indexes as a rudder. 
time, since the variations in relative prices in response to changes in the supply of money make the concept of general price level meaningless.

As we have seen, for Mises, money: (a) has a value defined by the «intensity of the desires» of each individual in the market and totally severed from its "previous source of value», and (b) has features that had evolved (until 1912) to a level of detachment from commodity money that was difficult to grasp. Now, it is possible to conclude that, for Mises, money had been in the path for increasingly more abstract forms as hypothesized by Simmel.

IV

SIMMEL'S PHILOSOPHY OF MONEY

\section{The subjectivity of any evaluation}

Simmel starts his discussion about value of money arguing that in nature objects have no value, it is only human beings that classify them by giving them value that are independent of their natural attributes; therefore, laying the basis for his claim about the subjectivity of value against any attempt to attribute objective value to the goods (Simmel 2001: 59).

This evaluation is part of this world, though; it is real, although the criteria utilized are psychological ones, reason why he calls them subjective. He makes clear that value is attributed to the goods as a consequence of their qualities (being them real or imaginary). But since there are many different ends for the individuals doing the evaluations, goods with apparently minimal utility for some may be extremely valued for others:

The characteristic feature of value, as it appears in contrast with reality, is usually called its subjectivity. Since one and the same object can have the highest degree of value for one soul and the lowest for another... (Simmel 2001: 62). 


\section{Evaluations are subjective but not capricious}

However, it is important to note that, for Simmel, subjective as value may be, it is not devoid of a relation with reality, it is not mere caprice; and the recognition of some good's economic value is nothing more than making «objective» the subjective values of the economic agents (Simmel 2001: 65).

But note the unusual sense in which Simmel utilizes the concept of «objective» value. Objective value is here the actualization of personal preferences in exchange; and not, like a medieval theorist would regard, as something objective:

In the Middle Ages, it was assumed that there was a direct relation between object and money-price i.e. a relation based upon the independent value of each, which could and should find a «just» expression (Simmel 2001: 126).

Let's concede that Simmel here, in referring to just price, is traveling in murky territory, but still the point that he seems interested in stressing is that value arises from the act of exchange and not that it is intrinsic in the goods exchanged: ${ }^{6}$

Thus there may be, indeed, a just price for a commodity, but only as the expression of a definite, well-adjusted exchange relationship between this commodity and all others, and not as a consequence of the nature of the commodity itself or the amount of money itself, which stand in no relation to each other and have no reference to the just or the unjust (Simmel 2001: 127).

\section{Scarcity and utility, the sources of value}

As it was said before, for Simmel, the value of a good is contingent on its scarcity: «The first requirement for an economic object to exist, based upon the disposition of the economic subject, is

${ }^{6}$ Furthermore, we will see an echo of this reasoning later on when Simmel argues for the stability of money value as derived from exchange. 
utility. To this, scarcity must be added as a second determining factor if the object is to acquire a specific value» (Simmel 2001: 91). «What is really meant is the desire for the object». «Real demand» is different from «Wish».

Therefore, according to Simmel, subjectivity of value does not mean that value is independent of the object. It is true that, for him, evaluation is a sentiment, but value cannot be derived from the evaluator or from the object of evaluation because it is a relation between the two (Simmel 2001: 68).

A good example of that is found in his description of why precious metals are proper to be used as money. One component of their value as media of exchange is scarcity, but they cannot be too scarce, it is scarcity above a minimum that makes precious metals adequate for monetary use; and that is true because the monetary «attribute» of precious metals depends on them being "generally accepted» as medium of exchange, and if they are too scarce, the quantity necessary for being commonly used will not be available (Simmel 2001: 72).

\section{Economic value}

There is in Simmel a restatement of Menger's theory of value, although there are no explicit references to that. For Simmel, exchanges are done at objectively equivalent prices, but that does not imply that the subjective evaluations of the traders are the same. Although the agents agree on an objective price to clear their transaction, their marginal preferences are determined subjectively, there is no way that that could be different:

This emphasis arises from the fact that objects have to be paid for by the patience of waiting, the effort of searching, the exertion of labor, the renunciation of other things in demand... In conceptual terms, price coincides with the economically objective value (Simmel 2001: p. 93).

To say that economic value is objective is tautological for Simmel: 
Value is, so to speak, the epigone of price, and the statement that they must be identical is a tautology (Simmel 2001: 94).

Economic value is, therefore, the monetary representation that embodies the subjective evaluation of the economic agent. Economic value is not an attribute of the object. It is detached from the sentiments of the evaluator and from the causes for his sentiments; it is, in a word, an abstraction, or in Simmel's words:

money is the incarnation and purest expression of the concept of economic value (Simmel 2001: 101).

\section{The inter-subjectivity of money value}

We can say therefore that, for Simmel, value is neither purely objective nor subjective, but it is inter-subjective. With this concept, Simmel adds one step to the previous understanding about money. The mere statement that there is subjectivity and objectivity in the value of money would already put Simmel ahead of the neoclassical economists at his time, but the same concept is already present in Menger as we saw before.

\section{The stability of money value}

Simmel needs to develop an explanation for the stability of value of money (as it was perceived in 1900) and he founds that explanation on the inter-subjective source of money value.

It is not only that money has an objective value, as we can find in any given transaction cleared by money, but also that value had been (at least for almost a century before 1900) remarkably stable. From the inter-subjective source of money value, Simmel derives its perceived stability. For that sort of modern society, urban, cosmopolitan societies of Europe des fins de siècle, money had been a stable reference for individual exchanges, in middle of all of the turmoil of war, revolutions, the eruption of nationalisms, etcetera; and yet, money value is not something intrinsic in the monetary commodity: 
In exchange, value becomes supra-subjective, supra-individual, yet without becoming an objective quality and reality of the things themselves (Simmel 2001: 78).

But according to Simmel, how does money value become stable? He argues that the money price of every merchandise indicates the degree of exchangeability of that good for all the other goods; to the extent that money expresses the relative value of the different goods, it becomes useful in two ways, first, as an abstract system of measurement (unit of account) and second, as a medium of exchange. But in order to do that, money must be outside the same realm of every other merchandise:

In order to perform theses services, which depend upon its position outside all other goods, money has to be a concrete or specific value itself; and by performing these services it becomes such a value (Simmel 2001: 122).

According to Simmel, the stability in money value is acquired by the utility in exchange that is generated to all the economic agents precisely by their preference in using a given monetary merchandise as medium of exchange. Its value is determined fundamentally by the sum of the individual preferences, although Simmel recognizes that (at his time of commodity money) the production cost of the monetary merchandise would be also a component of its value:

Its value becomes dependent upon supply and demand; its costs of production exert an influence, however slight, upon its value (Simmel 2001: 122).

The monetary merchandise gains an autonomous and stable source of value in exchange; and Simmel brings the fact that the economic agents are willing to pay interests to dispose of money as a further evidence that it has a value on its own:

The payment of interest is a manifestation of this value which results from the functions of money (Simmel 2001: 122). 
Nowadays, with fiat money, this test gains even more relevance, since the economic agents continue to be willing to pay interests in order to dispose of what is, in essence, aside from its value in exchange, valueless.

\section{The essential quality of money}

For Simmel, money has an essential quality that relates it with everything and at the same time detaches money from everything else:

Since the basic characteristic of all knowable existence, the interdependence and interaction of everything, also refers to economic value and conveys this principle of life to economic material, the essential quality of money now becomes comprehensible. For the value of things, interpreted as their economic interaction, has its purest expression and embodiment in money (Simmel 2001: 119).

\section{Money evolves}

For Simmel, money embodies all inter-subjective evaluations of all goods in an amazingly stable fashion. However, money as that abstract, stable, reference of value is not something that came into being in the shape observed at his time; without committing himself to the controversy about the origin of money, Simmel states the evolutionary characteristic of monetary institutions:

Whatever may be the historical origin of money —and this is far from being clearly established-one fact at least is certain, that money did not suddenly appear in the economy as a finished element corresponding to its purest concept (Simmel 2001: 119).

According to Simmel, it is clear that the monetary characteristics, that is, the attributes that make some goods to be seen as media for indirect exchanges, evolved from the value of certain goods for other purposes: 
Money can have developed only out of previously existing values in such a way that the quality of money, which forms part of every exchangeable object, was realized to a great extent in one particular object; the function of money was at first still exercised, as it were, in intimate association with its previous value significance (Simmel 2001: 119).

What remains to be seen is if, for Simmel, the connection between the monetary and the non-monetary value of money can ever be dissolved.

And Simmel answers that question in the affirmative. Money, in its pure essence, has a value that exists apart from any other quality:

It can be seen that money constitutes one party, as it were, and the totality of goods bought by money constitutes the other party; so far as its pure essence is concerned, it must be interpreted simply as money, quite apart from all the secondary qualities that connect it with the contrasting party (Simmel 2001: 120).

\section{Money as a substance with abstract value}

For Simmel, as already mentioned, money evolved from the most concrete kinds of goods to increasingly abstract forms. Since the very moment of the introduction of a medium of exchange in society, the use of money has been an evolutionary process. In this process, it is possible to identify, since the first steps, a tendency towards the dissociation between the direct utility of some goods (the ones that eventually became the monetary merchandize) and their indirect utility:

If money has its origin in barter, it begins to develop only when a single object is exchanged not against another single object but against several others (Simmel 2001: 127).

Simmel mentions that one of the main hazards with barter is the problem of divisibility. Patently, that is not the main hazard 
with bartering, the hazards associated with finding counterparts interested in what you have to offer seem to be a much more important aggravation (in a post Coasean time, we can talk about the transaction costs involved in bartering), still it is not to neglect that it is difficult to grasp how many chicken eggs value a house if the only medium of exchange you have is a cow, or in Simmel's words:

The most developed form of divisibility is attained with exchange against money. Money is that divisible object of exchange, the unit of which is commensurable with the value of every indivisible object; thus it facilitates, or even presupposes, the detachment of the abstract value from its particular concrete content (Simmel 2001: 128). ${ }^{7}$

So, money is the instrument to foster indirect exchanges which evolves as required by an increasing complexity of the indirect transactions. One of the key steps in its evolution is to become divisible to infinitesimal amounts, what allows the traders to nominate the price of their merchandise in monetary terms with great precision. This role as a unit of account is obviously a step towards abstraction. The concepts of «foot» or «inch» do not refer to actual foot or inch and the measurements in the metric system are entirely conventional, that is, arbitrary, and still they are not diminished in their utility for that. Money as an instrument for indirect exchanges performs the role that the abstract concepts of meters and centimeters perform in measuring a room, for example. For Simmel, value is an emotion, it is something that can only be felt at a subjective level; still, it is something that the economic agents grade when attributing economic value to the different goods and in its function either as a unit of account or as a medium of exchange, money is at the same time the gauge and the instrument to the satisfaction of the desire for external goods. The performance of these functions puts money, as an instrument, in a perfectly abstract position, according to Simmel:

7 Incidentally, here Simmel seems to be talking about coined money and not any GAMOE. 
Because money is simply the means to acquire objects, it stands by its very nature at an insurmountable distance from the Ego which craves and enjoys; and in so far as it is the indispensable means between the Ego and the objects, it places the objects, too, at a distance. To be sure, money abolishes the distance again; but by doing so, by transferring the objects to subjective use, it removes them from the objective economic cosmos (Simmel 2001: 128).

Finally, Simmel brings to fore the concept of conventional symbolism. In our social life, there are numerous instances in which certain social relations are given symbols to represent them; and we can infer money is just one more of these cases:

It is a basic fact of mental life that we symbolize the relations among various elements of our existence by particular objects; these are themselves substantial entities, but their significance for us is only as the visible representatives of a relationship that is more or less closely associated with them. Thus, a wedding ring, but also every letter, every pledge, every official uniform, is a symbol or representative of a moral or intellectual, a legal or political, relationship between men (Simmel 2001: 129).

\section{The greatest triumph in money}

As it has been made clear by now, money epitomizes the pinnacle of abstraction. For Simmel, the capacity of the human mind to create abstractions is perfected with the introduction of a unit of account and of a medium of exchange in social relations. As mentioned before, it is not only the fact that money as an abstraction facilitates indirect exchanges, but that it facilitates those exchanges by the reification of many subjective evaluations:

The projection of mere relations into particular objects is one of the great accomplishments of the mind; when the mind is embodied in objects, these become a vehicle for the mind and endow it with a livelier and more comprehensive activity. The ability to construct such symbolic objects attains its greatest triumph in money. For 
money represents pure interaction in its purest form; it makes comprehensible the most abstract concept; it is an individual thing whose essential significance is to reach beyond individualities (Simmel 2001: 129).

\section{A judgment of reality:}

\section{The evolution of money is towards abstraction}

At a time when money was still perceived to be a commodity money, when bank notes were rightly or wrongly understood as equivalent to warehouse warrants on deposited precious metals, to say that the value of money, in its pure essence, was totally disconnected from any consideration other than its utility as medium of exchange was really visionary.

Note that Simmel here is not doing a value judgment, he is not stating that it is a good thing that the medium of exchange can be purely abstract, he is only stating that in fact it has something of an abstraction:

In this sense money has been defined as abstract value (Simmel 2001: 120).

For him, the significance of money is that it expresses the relativity of objects of demand through which they become economic values; such significance is not negated by the fact that money has also other qualities that may diminish and obscure its significance, but when that happens, we do not have money in its pure form:

In so far as these qualities are effective, it is not money proper (Simmel 2001: 130).

\section{Was Simmel talking about fiat money?}

Personally, I doubt that Simmel envisaged the replacement of commodity money for fiat money. Certainly, his groundbreaking hypothesis would argue that the outcome of a world monetary 
order only with fiat money would be perfectly possible, as the world where we have lived in since 1971 has proved. Money can be just the reification of economic value:

As a visible object, money is the substance that embodies abstract economic value (Simmel 2001: 120).

Money, as representative of abstract value, becomes the autonomous expression of the mutual relations of exchangeability.

\section{Ideal Money}

According to Simmel, the ideal money is the purely abstract money and the argument against abstract money can be summarized by saying that money better performs its monetary role when it does not simply represent «the value of things in pure abstraction». Those who think that way are, for instance, the ones that see in the industrial uses of precious metals something that adds to the monetary value of those metals (Simmel 2001: 165).

\section{The displacement of Goals}

We have seen so far that for Simmel, money is something that can have no other value on its own than the value that it achieves as an instrument for indirect exchange for the achievement of everything else. In this sense, the desire for money seems to be the desire for the power of having what money can buy, but then, for some, money becomes an object of desire by itself. It becomes the classic example of the displacement of goals. At first, money is valued purely as a means to an end: money is merely of an instrumental value, not an intrinsic value. But over time, some in society begin to value money for its own sake. The universal instrument becomes the universal goal. 
Alienation

This theme is not new. Discussions about the manifold forms of alienation engendered by capitalism, including the desire for money are an infamous feature of Karl Marx thought. What is new in Simmel is that the alienation induced by money is not inherent in "capitalism» but it is inherent in any modern society with the intense division of labor and indirect exchanges that only sophisticated forms of money can allow.

For Simmel, valuation is a subjective and individual appraisal, but through social intercourse and exchange, subjective values become objectified in norms and prices. Money is a uniquely objective yet abstract metric whereby all values can be reduced to a common denominator. The abstraction of value inherent in modern money is the reason for this alienation, and not "capitalism», Simmel argues.

\section{$\mathrm{V}$ \\ CONCLUSION}

\section{Money as the sole stable value in modern society}

At this moment, it seems relevant to question the reason for the development of the concept of intersubjectivity in Simmel's theory. It is my hypothesis that he needs an idea of objective value that is more than any value that happens to be agreed by the parts in a given transaction, he needs a value that emerges from the sum of all preferences. ${ }^{8}$ The reason is that Simmel, who started his inquiry as a subjectivist, sees that without an explanation for the stability of money value, without an account for the extraordinary stability of the objective value of money experienced in Western

8 The concept of objective value for Simmel means that, in terms of economic evaluations, it is possible to say that there is an objective value when different agents for different reasons come to the same conclusion about the monetary value that some good has for them:

The equation, objectivity = validity for subjects in general, finds its clearest justification in economic value (Simmel 2001: 81). 
societies under the gold standard, he would be unable to take yet one further step in his reasoning.

This further step is the statement that money is the fixed reference around which we assess the value of all other goods in modern society. Money for Simmel has a stable value in modern society. For him, money is the sole stable reference of value:

Thus it becomes comprehensible that money as abstract value expresses nothing but the relativity of things that constitute value; and, at the same time, that money, as the stable pole, contrast with the eternal movements, fluctuations and equations of the objects (Simmel 2001: 121).

Here, the main characteristics that Simmel finds in money come together, abstraction, inter-subjective source of value and stability: (A) The fact that money is abstract, or in other words, that the monetary merchandise at its current value is of no utility other than the one found in exchange, is perceived as essential for its purpose as unit of account and medium or exchange:

If money itself were a specific object, it could never balance every single object or be the bridge between disparate objects (Simmel 2001: 125).

And (B) Simmel argues that one of the most extraordinary and useful characteristics of money is the stability of its value. And this stability of value as it is revealed by the multitude of economic agents in the market exchanges comes from the fact that money is devoid of other actual qualities; again, it comes from the fact that it is an abstraction:

This significance of money shows itself further, in an empirical way, as stability of value, resulting from its interchangeability and lack of specific qualities. This is regarded as one of the outstanding and most useful characteristics of money (Simmel 2001: 125).

To conclude this section about the stability of money value, it is perhaps worthwhile to mention what for Simmel is the 
opposite of that. For Simmel, an increase in the general price level represents the destruction of the stability of value of the currency:

A general rise in prices would indicate a decrease in the value of money, and when that occurs the stability of money value is destroyed (Simmel 2001: 125).

At the time of Simmel, a time of universal (non-national) commodity money, with episodes of inflation under paper money or debasement far in history or geography, it is not difficult to imagine why our author does not elaborate on the cases in which that could happen. At his time, money would be the actual gold coins deposited in a bank vault and redeemable at request by cashing a banknote. One may wonder that money would only have its value decreased in the case of a cataclysmic event that would destroy part of money utility as an instrument for indirect exchanges at a global scale. Today, with national fiat money all around us, that phenomenon is much easier to grasp.

\section{BIBLIOGRAPHICAL REFERENCES}

Andreau, J. (1999): Banking and Business in the Roman World, Cambridge, UK: Cambridge University Press.

Crespo, O.V. (2004): «La fundamental homogeneidad de las teorias monetarias de Georg Simmel y Ludwig von Mises» in Procesos de Mercado, Volumen I, Numero 1, Primavera, 223-250.

KeYneS, J.M. (1997): The General Theory of Employment, Interest, and Money, New York, NY: Prometheus Books.

KnApp, G.F. (2003): The State Theory of Money, San Diego, CA: Simon Publications.

Mann, F.A. (1982): The Legal Aspect of Money, Oxford, UK: Oxford University Press.

Menger, C. (1994): Principles of Economics, Grove City, PA: Libertarian Press.

Mises, L. von (2007): Human Action, a Treatise on Economics, Indianapolis, IN: Liberty Fund. 
- (1980): The Theory of Money and Credit, Indianapolis, IN: Liberty Fund.

RostovtZefF, M. (1926): The Social \& Economic History of the Roman Empire, London, UK: Clarendon Press.

Simmel, G. (1971): «The Metropolis and the Mental Life» in On Individuality and Social Forms, Edited by Donald N. Levine, Chicago, IL: The University of Chicago Press, 324-339.

- (2001): The Philosophy of Money, London, UK: Routledge. 